\title{
4 \\ Formação Inicial de Professores \\ e Crenças de Autoeficácia para \\ Ensinar Educação Física na \\ Escola
}

\section{Roraima Alves da Costa Filho ${ }^{1}$ \\ Roberto Tadeu laochite ${ }^{2}$}

Temos acompanhado um aumento preocupante nos índices de sedentarismo e obesidade nas diferentes etapas do desenvolvimento humano. Adultos têm, cada vez menos, praticado atividade física, seja em momentos de lazer, seja para manter a forma física. Crianças têm despendido mais tempo em atividades de lazer sedentárias (videogames, por exemplo), que outrora (BRASIL, 2017; DUMITH, 2009). Pesquisas recentes realizadas em diferentes países têm mostrado que o nível de atividade física realizada por crianças e adolescentes tem sido cada vez menor (KNUTH; HALLAL, 2009). Além do sedentarismo, os maus hábitos alimentares (refeições desbalanceadas, refeições rápidas, alto consumo de fast food) constituem um problema epidêmico, que contribui para o desenvolvimento de doenças crônicas (ASSOCIAÇÃO BRASILEIRA PARA O ESTUDO DA OBESIDADE E DA SÍNDROME METABÓLICA, 2016).

Os impactos das doenças crônicas decorrentes da escolha por um estilo de vida não saudável - por exemplo, diabetes, hipertensão arterial e osteoartrite - já são sentidos nos cofres públicos. Estimase que os Estados Unidos gastam em média US\$ 147 bilhões

Apoio

${ }^{1} \mathrm{FAPESP}$

\#2015/06312-0

\#2016/05946-8

${ }^{2}$ PIBID/CAPES $\# 61 / 2013$ com o tratamento de doenças causadas pelo sedentarismo e pela obesidade tanto de adultos, como também de crianças em idade escolar. No Brasil, o Sistema Único de Saúde (SUS) teve um gasto de aproximadamente $\mathrm{R} \$ 3,6$ bilhões anuais entre 2008 e 2010 para o tratamento de doenças crônicas ligadas ao sobrepeso e obesidade (BAHIA; ARAÚJO, 2014). 
Autoeficácia em Contextos de Saúde, Educação e Política

Roberto Tadeu laochite \& Roberta Gurgel Azzi

Organizadores

para continuar lendo, clique aqui 